\title{
Comparison of outcomes of two methods of axillary osmidrosis surgery: Subdermal excision versus liposuction combined with diode laser ablation
}

Sung Won Jung ${ }^{1}$, Seung Je Lee ${ }^{1}$, Hye-Rim Park ${ }^{2}$

${ }^{1}$ Department of Plastic and Reconstructive Surgery, Hanil General Hospital, Seoul; ${ }^{2}$ Department of Pathology, Hallym University Sacred Heart Hospital, Anyang, Korea
This article is a part of Sung Won Jung's doctoral dissertation submitted in 2018.
Background Patients with axillary osmidrosis suffer from a foul odor due to the bacterial decomposition of apocrine gland secretions. This condition is stressful, especially for teenaged students and young working people in Korea, who seek a reliable method for reducing odor that allows them to quickly return to school or work after surgery. Thus, surgeons must seek ways to effectively remove sweat glands with minimal complications. The conventional subdermal excision method has been widely used for the removal of sweat glands, but it can have many complications. The purpose of this study is to determine whether liposuction combined with diode laser ablation is effective for sweat gland removal compared with the subdermal excision method.

Methods From 2011 to 2017, we compared two surgical methods for osmidrosis: subdermal excision and liposuction combined with diode laser ablation. An objective analysis of sweat (apocrine) gland count, determined by histopathological examinations of preoperative and postoperative punch biopsy specimens, was combined with a subjective assessment of patients' symptoms (malodor grade) preoperatively and postoperatively.

Results A larger percentage of sweat glands were removed by subdermal excision than by liposuction with diode laser ablation. However, no statistically significant difference was found between the two methods with regard to the percentage of apocrine glands removed. Liposuction with diode laser ablation had fewer perioperative complications and higher patient postoperative satisfaction than subdermal excision.

Conclusions Liposuction with diode laser ablation is a useful method for axillary osmidrosis surgery in teenaged students and young working people in Korea.

Keywords Apocrine glands / Lasers / Lipectomy / Sweating
Received: Sep 9, 2019 Revised: Oct 7, 2019 Accepted: Oct 22, 2019 Correspondence: Sung Won Jung Department of Plastic and Reconstructive Surgery, Hanil General Hospital, 308 Uicheon-ro, Dobong-gu, Seoul 01450, Korea

Tel: +82-2-901-3109, Fax: +82-2-901-3114, E-mail: underwood21@hanmail.net Copyright @ 2020 The Korean Society for Aesthetic Plastic Surgery.

This is an Open Access article distributed under the terms of the Creative Commons Attribution Non-Commercial License (https://creativecommons.org/licenses/by-nc/4.0/) which permits unrestricted non-commercial use, distribution, and reproduction in any medium, provided the original work is properly cited. www.e-aaps.org

\section{INTRODUCTION}

Axillary osmidrosis has multiple causes, the most prominent of which is excessive apocrine gland secretion induced by androgens [1]. An unpleasant odor is produced when bacteria decompose the apocrine secretions [2]. The acrid odor produced by osmidrosis can cause social embarrassment in Korea, especially among teenaged students and working people.

Removal of sweat glands, particularly the apocrine glands, has been introduced to treat axillary osmidrosis, with techniques in- 
cluding manual subdermal shaving of the apocrine glands and subcutaneous tissues, superficial liposuction curettage, carbon dioxide laser vaporization, and ultrasound-assisted suction aspiration [1]. More recently, various other methods, such as microwave-based therapy, percutaneous ethanol injection, and Versajet-assisted hydraulic epilation, have been introduced [3-5].

However, these methods can have various complications, such as hematoma, seroma, superficial epidermal necrosis, and full-thickness skin loss, as well as recurrence or remnant symptoms. Surgeons continue to seek methods to effectively reduce odor and lessen complications that impact school or work, especially in Korea.

Many plastic surgeons in Korea have used the conventional subdermal excision method for sweat gland removal due to its effectiveness. However, it can have postoperative complications, such as those previously listed. Notably, skin flap necrosis and prolonged recovery time are cumbersome complications of this method.

To avoid these complications, we combined liposuction with diode laser ablation. This method is simple and safe compared with the conventional subdermal excision method. If similarly effective, liposuction with diode laser ablation may replace the conventional subdermal excision method for axillary osmidrosis surgery.

\section{METHODS}

This study was approved by the Institutional Review Board of Hallym University Sacred Heart Hospital (IRB No. 2018I006).

From 2011 to 2017, 111 patients underwent osmidrosis surgery at our hospital, and we studied their cases retrospectively. Among them, 66 patients were evaluated through pathological examinations and assessments of odor grade. Patients younger than 15 years or older than 35 years were excluded because of their age. In total, 42 patients were excluded because relevant data were missing from their records. Furthermore, three patients younger than 15 years excluded because they underwent surgery under general anesthesia. Only patients who underwent a primary operation under local anesthesia were included; reoperation cases were excluded. This left 66 patients, who were evaluated by questionnaires and axillary biopsies.

In our study, we performed preoperative and postoperative punch biopsies of the axillae. We then assessed the number of sweat glandsmainly apocrine glands-present in the preoperative and postoperative punch-biopsied specimens using histopathological exami- nations conducted by pathologists with hematoxylin and eosin stain. We compared the results of this analysis for the subdermal excision group with those for the liposuction with diode laser ablation group. Additionally, our study included a subjective assessment of axillary odor performed by two surgeons (SWJ and Woong Kyu $\mathrm{Na}$, Hallym University Sacred Heart Hospital) and two nurses (Soojin Kwon, Seungmi Lee, Hallym University Sacred Heart Hospital), conducted both preoperatively and 6 months postoperatively using Park and Shin odor grading system (Table 1) [1]. All patients were asked to wear only a light cotton shirt during their physical examinations, which took place in a closed examination room. The strength of the odor was evaluated by rubbing the armpit with gauze and assessing the odor, as well as noting any malodor from the body, with the patients placed approximately $1.5 \mathrm{~m}$ away from the doctor and nurse [1]. We measured the grade of axillary malodor preoperatively and 6 months postoperatively. In the results, odor grade improvement refers to an improvement from preoperative grade to postoperative grade (Table 2).

All operations were performed under local anesthesia using $2 \%$ lidocaine with 1:100,000 epinephrine or using the tumescent technique. All patients were in the supine position, with their arms abducted approximately $90^{\circ}$. The main target was the hair-bearing area of the axillae, with its high density of apocrine and eccrine glands (Fig. 1).

Prior to making the skin incision (preoperative) and just prior to the closure of the axillary incision wound (postoperative), preoper-

Table 2. Comparative data of postoperative satisfaction and postoperative odor grade improvement

\begin{tabular}{lccc}
\hline Group & $\begin{array}{c}\text { Subdermal } \\
\text { excision } \\
\text { (n=28) }\end{array}$ & $\begin{array}{c}\text { Liposuction } \\
\text { combined with } \\
\text { diode laser } \\
\text { ablation (n=37) }\end{array}$ & P-value ${ }^{\text {a) }}$ \\
\hline Postoperative satisfaction & $10(36)$ & $15(40)$ & 0.951 \\
Satisfied & $15(54)$ & $18(50)$ & \\
$\begin{array}{l}\text { Acceptable } \\
\text { Unsatisfied }\end{array}$ & $3(10)$ & $4(10)$ & 0.005 \\
$\begin{array}{l}\text { Postoperative odor grade } \\
\text { Improvement }\end{array}$ & $27(96)$ & $25(67)$ & \\
\hline
\end{tabular}

Values are presented as number $(\%)$.

${ }^{a l}$ Chi-square test.

Table 1. The grading system for osmidrosis malodor initially described by Park and Shin [1]

\footnotetext{
Grade 0: Gauze rubbed on the armpit gave off no malodor under any circumstances

Grade 1: Gauze rubbed on the armpit gave off a slight malodor only after the patient performed strenuous activity (exercise, rigorous walking, etc.)

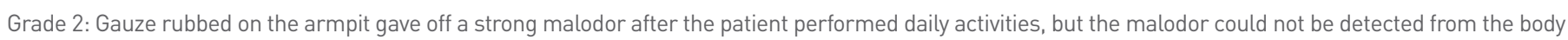
at a distance of $1.5 \mathrm{~m}$

Grade 3: Gauze rubbed on the armpit gave off a strong malodor and prominent malodor from the body could be detected easily at a distance of $1.5 \mathrm{~m}$
} 


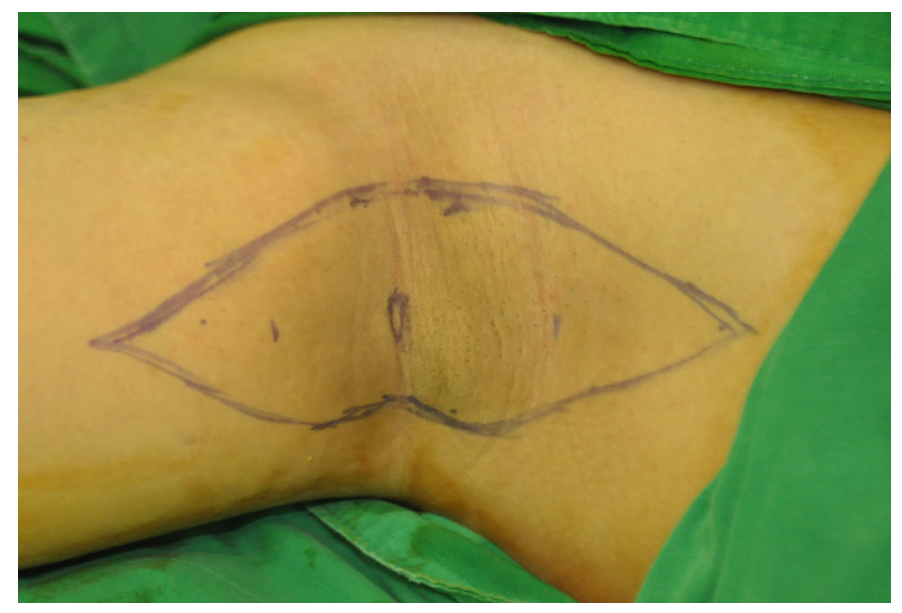

Fig. 1. Small tiny two stab incisions ( $3 \mathrm{~mm}$ each) for liposuction and laser ablation. Centrally round design for $3 \mathrm{~mm}$ punch biopsy preoperatively and just after postoperatively.

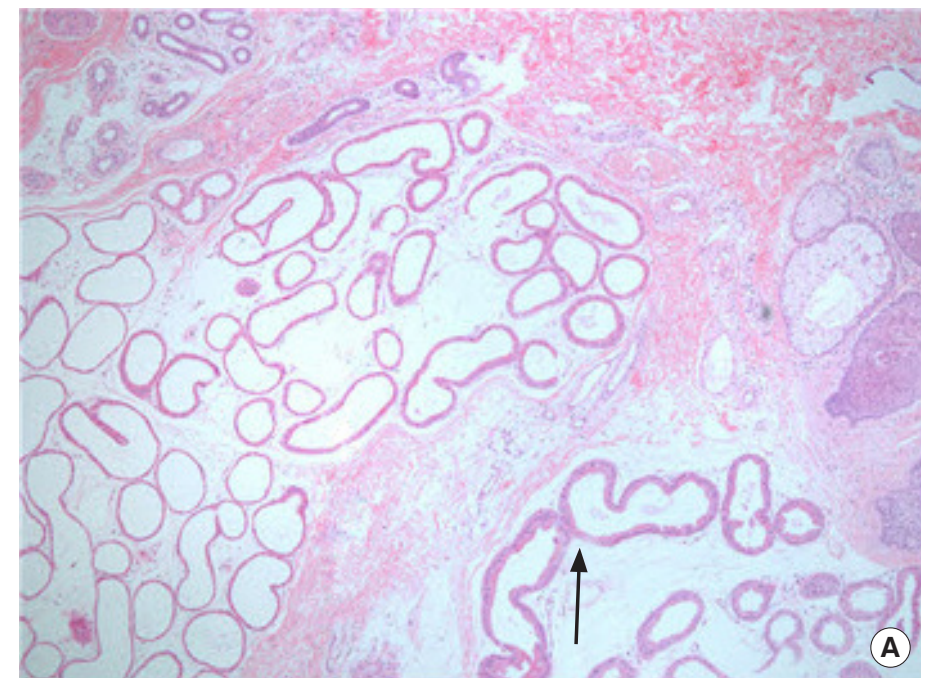

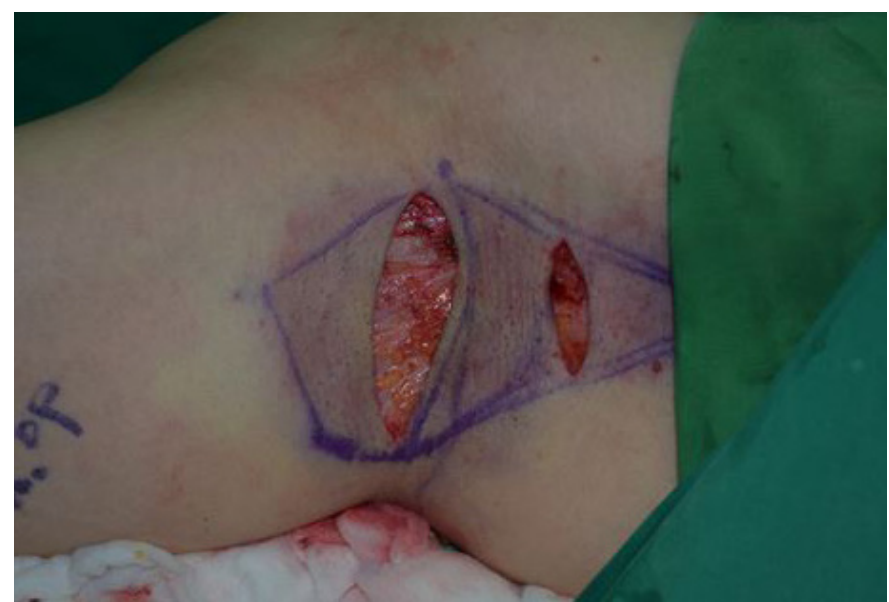

Fig. 3. Both sides of the subdermal layer were excised through each incision.

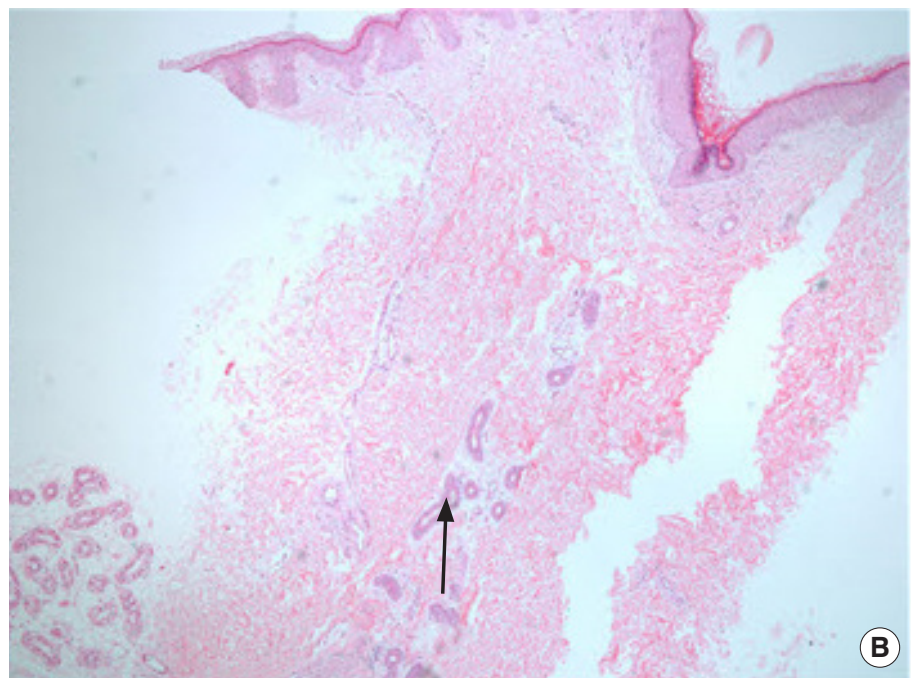

Fig. 2. (A) Preoperative and (B) postoperative sweat (apocrine) glands by H\&E stain of the punch-biopsied specimens (A: $\times 100, B$ : $\times 40$ ). After operation, the apocrine glands were decreased and few apocrine glands were remained postoperatively. The black arrow indicates apocrine.

ative and postoperative skin biopsies were performed with a 3-mmdiameter punch at the apex of the axilla to count the number of apocrine and eccrine glands present (Fig. 2).

\section{Subdermal excision}

Two subdermal incisions of approximately $4-5 \mathrm{~cm}$ were made along the vertical axillary crease in the hair-bearing area after local anesthesia (in 13 cases) or tumescent solution (in four cases) was administered to the entire operative area (Fig. 1). We used the twoincision method, rather than the single-incision method, to provide better exposure of the turnover flap and subcutaneous tissue. A 3-mm punch biopsy was performed at the deepest portion (the apex) of the axilla. After incision, we dissected the subcutaneous layer of the hair-bearing area superficial to the fascia, turned over the skin flap, and exposed the subdermal layer. Then, the region of the subdermal layer with a high density of apocrine and eccrine glands was excised with scissors, and both sides of the subdermal layer were excised through each incision (Fig. 3). We also excised the superficial layer of subcutaneous tissue beneath the undermined skin flaps (Fig. 4). We made efforts to avoid injuring the subdermal plexus of the overturned skin flaps during removal of apocrine glands. Next, a punch biopsy was performed near the site of the previous punch biopsy. After the insertion of two silastic drains, the incision wounds were closed using 5-0 Nylon sutures. The same method was used for the other axilla as well.

Finally, tie-over suturing was performed to prevent complications, such as hematoma and skin flap necrosis. The operation time was approximately $2-3$ hours. The dressing was opened on the sec- 


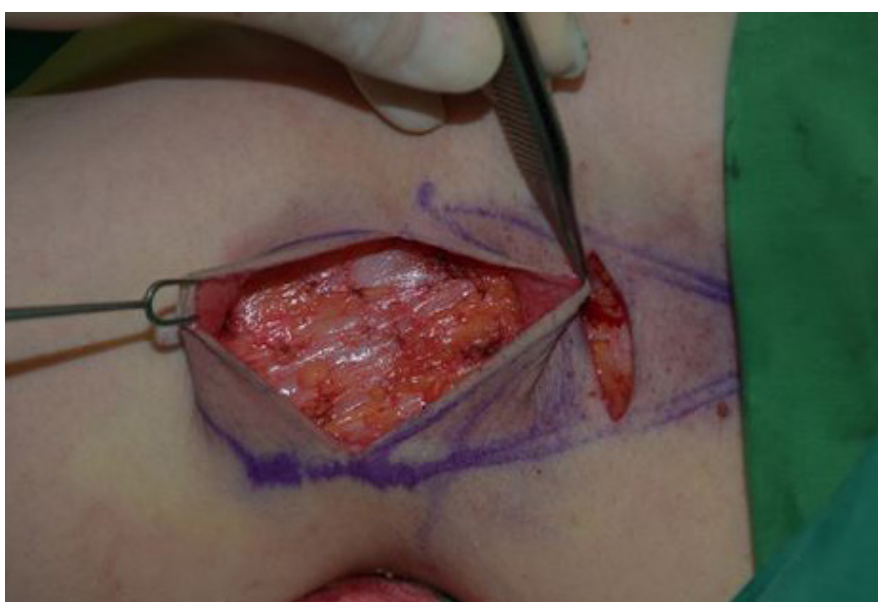

Fig. 4. After subdermal excision before wound closure, which showed complete removal of sweat glands in axillary hair-bearing area, suprafascially.

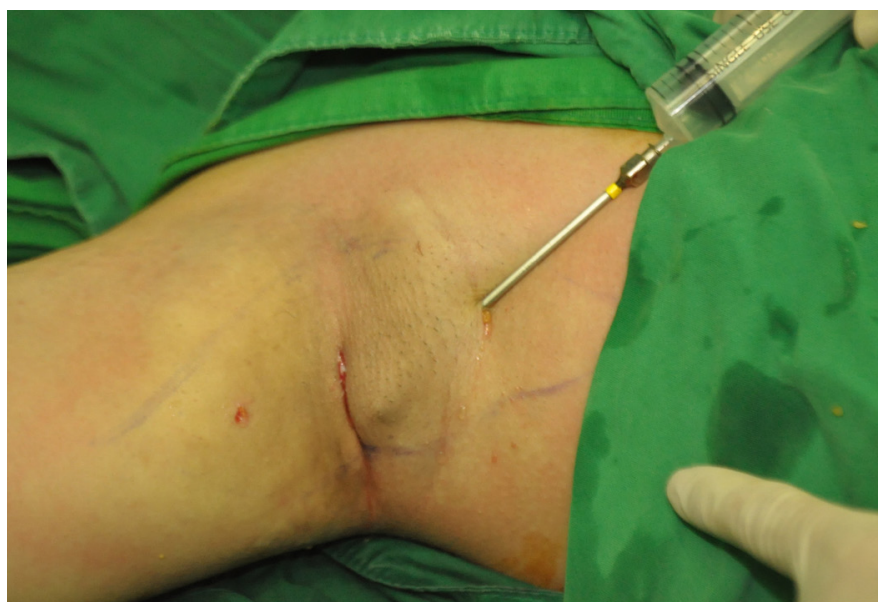

Fig. 5. Manual liposuction by cannula using $20 \mathrm{~mL}$ syringe with $5 \mathrm{~mL}$ negative pressure by crisscross patterns.

ond or third postoperative day, and patients were discharged on the 5 th postoperative day.

\section{Liposuction combined with diode laser ablation}

For this procedure, we used a blunt cannula with three holes; additionally, we used a Diomed Surgical laser (EVE 980; International Technology Corp., Daejeon, Korea), which is an 980-nm diode laser. We used a micro-cannula with a diameter of $1.5 \mathrm{~mm}$ to protect the surrounding tissue. This makes it easy to manipulate the heat source for the destruction of deep dermal apocrine and subcutaneous apocrine glands. The diode laser tip was introduced into the micro-cannula with $1.0-\mathrm{cm}$ long tip exposure to facilitate the destruction of apocrine glands.

Without shaving the hairs of the axillae, we made two stab incisions $(3 \mathrm{~mm})$ one-quarter and three-quarters from the top of the

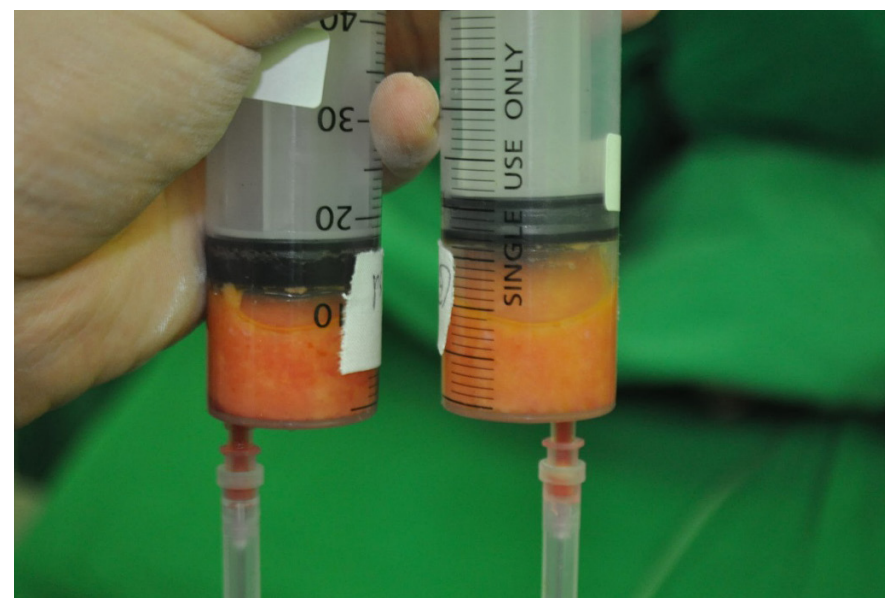

Fig. 6. After liposuction and then removal of water, 7-10 mL pure fat on each side of axilla. They were sent for H\&E staining and counting of the sweat (apocrine) glands.

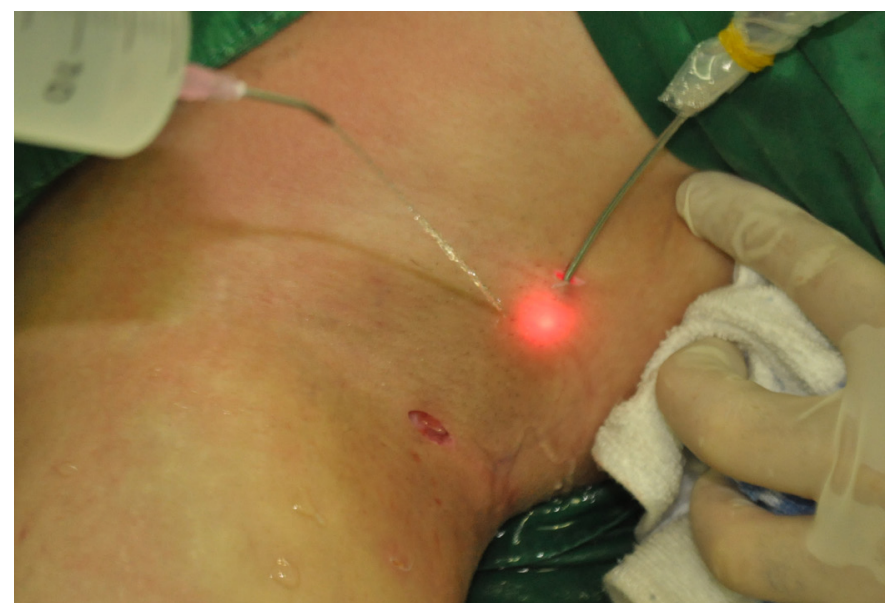

Fig. 7. During diode laser ablation, cold saline irrigation for prevention of thermal damage to skin flap.

marked hair-bearing area (Fig. 1). For liposuction, we infiltrated 200 to $300 \mathrm{~mL}$ of tumescent solution into the marked hair-bearing axillary area through the incisions in each axilla. We performed manual syringe liposuction with negative suction pressure of $5 \mathrm{~mL}$ using a $20 \mathrm{~mL}$ syringe (Fig. 5), and the aspiration volume was 15 to $20 \mathrm{~mL}$ from each axilla (7-10 mL of pure fat per axilla). Some of the aspirated fat was sent for histopathological examination (using a hematoxylin and eosin stain) to determine how many apocrine glands were removed (Fig. 6). We then performed ablation with a diode laser immediately after liposuction using the subcutaneous tunnels previously established in the liposuction procedure. We applied laser power only while performing an extraction or withdrawal motion with the diode laser. We scraped the undersurface of the skin flap in a crisscross pattern at a speed of approximately $5-15 \mathrm{~mm} / \mathrm{s}$, and to prevent thermal injury, we applied cold saline 
Table 3. Mean decreases in gland number after subdermal excision and liposuction combined with diode laser ablation

\begin{tabular}{lccc}
\hline Group & $\begin{array}{c}\text { Subdermal } \\
\text { excision }\end{array}$ & $\begin{array}{c}\text { Liposuction } \\
\text { combined with } \\
\text { laser ablation }\end{array}$ & P-value ${ }^{\text {al }}$ \\
\hline $\begin{array}{l}\text { Postoperative apocrine glands } \\
\text { No. of axillary glands }\end{array}$ & 17 & 75 & 0.069 \\
$\begin{array}{l}\text { Reduction in number of glands, } \\
\text { mean (reduction rate) }\end{array}$ & $35.71(78.99)$ & $23.47(52.83)$ & \\
$\begin{array}{l}\text { Standard deviation } \\
\text { Postoperative eccrine glands }\end{array}$ & 26.298 & 19.954 & \\
$\begin{array}{l}\text { No. of axillary glands } \\
\text { Reduction in number of glands, } \\
\text { mean (reduction rate) }\end{array}$ & $14.06(61.4)$ & $4.81(6.14)$ & \\
\begin{tabular}{l} 
Standard deviation \\
\hline
\end{tabular} & 14.656 & 13.335 & \\
\hline
\end{tabular}

alMann-Whitney U-test.

irrigation during the laser ablation and applied ice packs to the skin (Fig. 7). In total, each axilla was exposed to approximately ap-

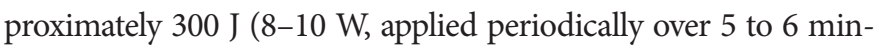
utes). We performed postoperative punch biopsies near the preoperative biopsy sites and sutured the punch biopsy wound sites with 5-0 Nylon sutures; the two stab incision wounds were left open for spontaneous drainage, and a simple light compressive dressing was applied. The same method was used for the other axilla. Punch biopsy was performed on the bilateral axillae in all but one patient. The operation time was around 1 hour shorter than that of the subdermal excision method. The two stab incisions were left open for tumescent drainage and spontaneous healing by secondary intention. Finally, we applied a light compressive dressing for 24 hours postoperatively; patients were discharged from the hospital on either the day of surgery or the next day.

For statistical methods, we used the Mann-Whitney U-test to assess differences between the two groups with regard to changes in sweat gland count (Table 3). Additionally, we used the chi-square test to assess differences between the groups with regard to postoperative patient satisfaction and odor grade improvement (Table 2). The intraoperative gross photos of the axillae were formally approved by the patient for use in this study.

\section{RESULTS}

The age distribution of patients was $15-35$ years, and the mean age was 23.7 years. The study consisted of 31 male and 35 female patients. All 66 patients underwent surgery primarily for axillary osmidrosis. Of these, 28 patients were treated with conventional subdermal excision, and 38 patients were treated with liposuction combined with diode laser ablation using an EVE 980 laser (Fig. 8). The wavelength of the laser was $980 \mathrm{~nm}$.

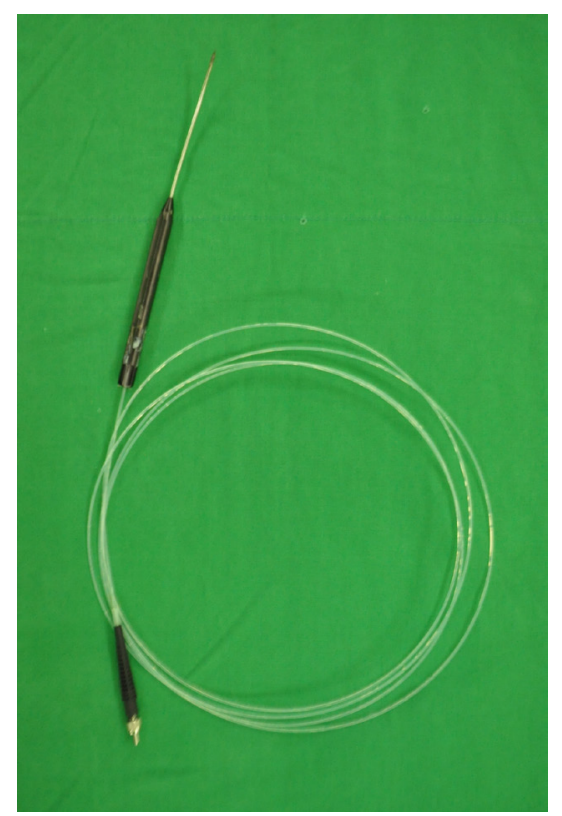

Fig. 8. Diode (Diomed Surgical) laser probe and cannula which ablates sweat glands by heat. The metal shield cannula prevents thermal damage from the laser heating except for the tip of the laser.

In the preoperative assessment of disease grade, 35 patients were characterized as having grade $0-1$ osmidrosis, 24 had grade 2 , and six had grade 3. Forty-eight patients (73\%) complained of adverse effects on their social lives because of their odor, and 17 patients (26\%) subjectively felt their axillary malodor to be moderate to severe, causing displeasure. We measured the grade of axillary malodor preoperatively and at 6 months postoperatively. From the first measurement to the second, the symptoms improved in a total of 52 patients (80\%). In the subdermal excision group, 27 patients (96\%) showed improvement in subjectively-assessed symptoms, compared with 25 patients (67\%) in the liposuction with diode laser ablation group (Table 2). The proportion of patients who showed subjective symptom improvement as assessed by doctors and nurses (postoperative odor grade improvement) was $80 \%$.

In the subdermal excision group, 10 patients (36\%) reported feeling satisfied, and three patients (10\%) complained of some complications. Two patients (7\%) underwent reoperation by liposuction with diode laser ablation, which yielded satisfactory results. In the liposuction combined with laser ablation group, 15 patients (40\%) reported feeling satisfied, and four (10\%) complained of insufficient improvement of symptoms; these patients underwent reoperation. Two of these reoperation patients were again treated with liposuction combined with laser ablation, while the other two patients were treated with subdermal excision (Table 2). The mean operation duration was 1 hour for liposuction combined with laser ablation and 2 hours for subdermal excision. The satisfaction rate was higher in the liposuction combined with laser ablation group 
Table 4. Reduction in hair and complications

\begin{tabular}{lcc}
\hline & $\begin{array}{c}\text { Subdermal excision } \\
\text { (n=56) }\end{array}$ & $\begin{array}{c}\text { Liposuction combined } \\
\text { with diode laser ablation } \\
\text { (n=74) }\end{array}$ \\
\hline $\begin{array}{l}\text { Reduced hair } \\
\text { Reduced }\end{array}$ & $51(91)$ & $9(12)$ \\
No change & $5(9)$ & $65(88)$ \\
Complications & & \\
Skin erosion & $13(23)$ & $14(19)$ \\
Hematoma & $7(12)$ & $2(3)$ \\
Skin necrosis & $2(3)$ & 0 \\
Scar contracture & $21(37)$ & $22(30)$ \\
Hypoesthesia & $17(30)$ & $7(9)$ \\
Brachial nerve injury & 0 & 0 \\
\hline
\end{tabular}

Values are presented as number $(\%)$.

(40\%) than in the subdermal excision group (36\%); however, the difference was not statistically significant $(\mathrm{P}=0.951)$ (Table 2$)$.

The pathologist counted the numbers of glands in the biopsy specimens using hematoxylin and eosin staining under $\times 100$ magnification, and compared with views under $\times 40$ magnification for convenience (Fig. 2). After subdermal excision, the number of apocrine glands decreased by approximately $79 \%$, whereas after liposuction with diode laser ablation, the number of glands decreased by approximately $53 \%$. However, the difference in reduction of apocrine glands between the two methods was not significant $(\mathrm{P}=0.069$, Mann-Whitney U-test) (Table 3).

The subdermal excision group had more perioperative complications, such as hematoma, skin necrosis, and scarring, than the liposuction with diode laser ablation group (Table 4). In the latter group, $30 \%$ of patients complained of mild, uncomfortable scar contracture in the part of the arm abducted after surgery, although the symptoms had spontaneously improved by 2 to 3 months later during outpatient department (OPD) follow-up.

Other complications of liposuction with diode laser ablation are shown in Table 4. However, these complications were transient and improved spontaneously during OPD follow-up without requiring a second operation.

In contrast, in the subdermal excision group, skin necrosis occurred in two patients (3\%). The wounds were healed with small local flaps made in the operating room during OPD follow-up. Other postoperative complications in the subdermal excision group improved spontaneously during OPD follow-up, but this improvement took more time than for the liposuction with diode laser ablation group.

After liposuction, we sent the aspirated fat samples (usually 7-10 $\mathrm{mL}$ per axilla) for a histopathological exam by pathologists (Fig. 6). These fat samples were found to contain both apocrine and eccrine glands. Therefore, we regard our liposuction method as also effec- tive for the removal of sweat (eccrine) glands.

Most patients who underwent liposuction combined with laser ablation were only hospitalized for 1 day, but subdermal excision required longer periods (5 days) for compression dressing, including the use of tie-over dressings. The patients who received liposuction combined with laser ablation were satisfied with their short hospitalization periods, few complications, and rapid return to ordinary life. In cases of reoperation due to dissatisfaction or recurrence, the same anesthesia method was used. In cases of recurrence, both surgical methods were effective; the subjectively-assessed symptoms improved, and the number of sweat glands decreased on pathologic exam.

\section{DISCUSSION}

Currently, many methods of treating axillary osmidrosis are known. Conservative treatments, such as topical and systemic agents and botulinum toxin, are only temporarily effective, making periodic application necessary [6].

Treatment methods include en bloc excision of the skin and subcutaneous tissue, suction curettage, shaving the subcutaneous sweat glands manually with or without carbon dioxide vaporization, and selective surgical excision of apocrine and eccrine glands [1]. More recently, various other methods, such as microwave-based therapy, percutaneous ethanol injection, and Versajet-assisted hydraulic epilation, have also been introduced [3-5].

En bloc excision is currently regarded as an overly aggressive surgical procedure for axillary osmidrosis due to its potential to lead to postoperative axillary contracture. Subdermal excision is much less aggressive than en bloc excision. Furthermore, subdermal excision is effective and relatively safe compared to other methods such as dermal curettage, as it avoids complications of subdermal plexus injury [7]. Currently, the subdermal excision method is widely used by many plastic surgeons in Korea as a standard definitive treatment method for axillary osmidrosis. However, this method may sometimes lead to postoperative complications such as flap necrosis due to subdermal plexus injury, requiring reoperation. Utilizing a tie-over dressing for 3 to 5 days is cumbersome, and hospitalization may therefore be required for 3 to 5 days for axillary immobilization. If complications occur, the hospitalization or treatment time is prolonged further.

In light of the previously-mentioned shortcomings, we attempted liposuction with diode laser ablation as a replacement for the conventional subdermal excision method. Liposuction with diode laser ablation is simpler and has fewer complications than the subdermal excision method. If the effectiveness of liposuction with diode laser ablation with regard to foul odor removal is the same or superior to that of the conventional subdermal excision method, many surgeons would choose this method.

We assessed the two methods using both subjective and objec- 
tive data. In our preoperative and postoperative surveys, the subjective data were the patients' complaints of symptoms, while the objective data were the apocrine and eccrine gland counts on intraoperative (just prior to the operation and just after the operation) punch biopsies.

Liposuction and diode laser ablation are independent surgical methods, although some reports have described a combination of methods. A study by Lee et al. [6] found that $98 \%$ of patients treated by liposuction with dermal curettage showed good to excellent results. In our study, we used diode laser ablation instead of dermal curettage. Histologically, diode laser ablation should remove apocrine glands in the subcutaneous layer more effectively than the curettage method proposed by Lee et al. As histological findings suggest, eccrine glands are dominant in the dermis, but most apocrine glands are located in the subcutaneous tissue and deep dermis [8]. Therefore, the diode laser ablation of apocrine glands in subcutaneous tissue and in the deep dermis is effective for eliminating apocrine glands [8]. This combined method should be more effective than other methods [7].

It is desirable for surgeons to know what percentage of the sweat glands can be removed using each operation method. Studies have reported comparative findings regarding apocrine gland counts. Bang et al. [9] conducted histopathological studies of the apocrine gland, and Kim et al. [10] studied the efficacy of subdermal excision and superficial suction in the removal of apocrine glands. Kim et al. counted the total number of apocrine glands in tissue specimens obtained using these two methods. The results showed a mean decrease of 127.82 apocrine glands $/ \mathrm{cm}^{2}$ with subdermal excision and a mean decrease of 72.71 glands $/ \mathrm{cm}^{2}$ with superficial suction $[2,9,10]$. The subdermal excision method was thus superior to the superficial suction method with regard to reduction in the number of apocrine glands.

Because no reports have identified how many apocrine glands should be removed to achieve an odor-free state after surgery, it is desirable to remove as many glands as possible. In this study, subdermal excision removed more sweat glands than liposuction combined with laser ablation, but this difference was not statistically significant $(\mathrm{P}=0.069)$. The subdermal excision group also exhibited more perioperative complications, such as hematoma, skin necrosis, and scarring, in addition to longer mean hospitalization periods than the liposuction combined with laser ablation group. Additionally, patients were subjectively more satisfied after liposuction combined with laser ablation, due to fewer complications and a shorter recovery time $[6,11,12]$ (Table 2). Moreover, postoperatively, liposuction with diode laser ablation requires only light dressing and a short hospitalization. The complications were usually transient and were easily treated during OPD follow-up.

In our study, in the liposuction with diode laser ablation group, the recurrence (reoperation) rate was $10 \%$, which is slightly higher than that found previously [13]. We suspect that this difference in recurrence rate might be due to the strict evaluation of odor grade involved in our method. The four reoperated patients who had undergone liposuction with diode laser ablation experienced symptomatic improvement due to the first procedure, but required reoperation for further improvements.

Though $80 \%$ of patients displayed subjective symptom improvement as assessed by doctors and nurses in our study, all patients reported symptomatic improvement after surgery. We evaluated the degree of odor using a 4-point scale, whereas other reports have evaluated degree of odor using a 10-point scale [3]. If we had evaluated degree of odor in the same way as those other reports, all patients would have shown a postoperative improvement in degree of odor.

The most common complication of liposuction combined with laser ablation is contracture. We suspected that this contracture is caused by thermal damage during diode laser ablation. Therefore, in young teenaged patients, we were careful to set the diode laser power as low as possible ( $8 \mathrm{~W}$ or below) and to keep application time shorter than for adults (under 5 minutes).

In the subdermal excision group, skin necrosis occurred in two patients (3\%). The wounds were healed by small local flaps in the operating room during OPD follow-up. Other postoperative complications required more time to resolve than the complications in the liposuction with diode laser ablation group.

Though the subdermal excision method is well known as a highly effective method for sweat gland removal, in our study, there was no statistical difference in apocrine gland reduction between the subdermal excision and liposuction combined with laser ablation groups. Additionally, postoperative patient satisfaction was higher in the liposuction with diode laser ablation group. Therefore, liposuction combined with laser ablation appears to be useful for these patients, especially teenaged students and working people in Korea.

The limitations of this study are as follows. The pathologist did not count apocrine glands in all hair-bearing areas of the axilla, but only at the apex punch biopsy area (which is usually the area of the axilla densest with apocrine glands). Additionally, there have been no studies on the number of apocrine glands that must be removed to relieve symptoms, so we could not compare our study with others in this regard. A long-term follow-up study, conducted more than 12 months after the operation and using a punch biopsy to obtain an apocrine gland count, would more accurately demonstrate the effects of this procedure.

\section{NOTES}

\section{Conflict of interest}

No potential conflict of interest relevant to this article was reported.

\section{Ethical approval}

The study was approved by the Institutional Review Board of Hal- 
lym University Sacred Heart Hospital (IRB No. 2018I006) and performed in accordance with the principles of the Declaration of Helsinki.

\section{Patient consent}

The patients provided written informed consent for the publication and the use of their images.

\section{ORCID}

$\begin{array}{ll}\text { Sung Won Jung } & \text { https://orcid.org/0000-0002-3883-5447 } \\ \text { Seung Je Lee } & \text { https://orcid.org/0000-0002-2946-009X } \\ \text { Hye-Rim Park } & \text { https://orcid.org/0000-0002-2976-5467 }\end{array}$

\section{REFERENCES}

1. Park YJ, Shin MS. What is the best method for treating osmidrosis? Ann Plast Surg 2001;47:303-9.

2. Perng $\mathrm{CK}$, Yeh FL, Ma H, et al. Is the treatment of axillary osmidrosis with liposuction better than open surgery? Plast Reconstr Surg 2004; 114:93-7.

3. Yang HH, Miao Y, Chen YT, et al. Minimally invasive approaches to axillary osmidrosis treatment: a comparison between superficial liposuction with automatic shaver curettage, subcutaneous laser treatment, and microwave-based therapy with a modified technique. J Cosmet Dermatol 2019;18:594-601.

4. Asilian A, Shahbazi M, Abtahi-Naeini B, et al. Percutaneous ethanol injection as a promising and minimally invasive treatment for axillary osmidrosis: double-blinded randomized controlled trial. Indian J Dermatol Venereol Leprol 2018;84:157-62.

5. Han JH, Kim JK, Yoon KC, et al. Versajet-assisted hydraulic epilation through small incisions for axillary osmidrosis. Aesthetic Plast Surg 2018;42:617-24.

6. Lee D, Cho SH, Kim YC, et al. Tumescent liposuction with dermal curettage for treatment of axillary osmidrosis and hyperhidrosis. Dermatol Surg 2006;32:505-11.

7. Qian JG, Wang XJ. Effectiveness and complications of subdermal excision of apocrine glands in 206 cases with axillary osmidrosis. J Plast Reconstr Aesthet Surg 2010;63:1003-7.

8. Kim IH, Seo SL, Oh CH. Minimally invasive surgery for axillary osmidrosis: combined operation with CO2 laser and subcutaneous tissue remover. Dermatol Surg 1999;25:875-9.

9. Bang YH, Kim JH, Paik SW, et al. Histopathology of apocrine bromhidrosis. Plast Reconstr Surg 1996;98:288-92.

10. Kim JR, Cha JH, Na MH, et al. Comparison of treatment effect between superficial suction and subdermal excision in osmidrosis. J Korean Soc Plast Reconstr Surg 2003;30:15-9.

11. Ichikawa K, Miyasaka M, Aikawa Y. Subcutaneous laser treatment of axillary osmidrosis: a new technique. Plast Reconstr Surg 2006;118: 170-4.

12. Tsai RY, Lin JY. Experience of tumescent liposuction in the treatment of osmidrosis. Dermatol Surg 2001;27:446-8.

13. Shin JY, Roh SG, Lee NH, et al. Osmidrosis treatment approaches: a systematic review and meta-analysis. Ann Plast Surg 2017;78:354-9. 